FINAL REPORT

\title{
Emissions Of Greenhouse Gases From Rice Agriculture
}

DE-FG02-04-ER63913

\section{Principal Investigator}

M.A.K. Khalil

Department of Physics, Portland State University, P.O.Box 751,

Portland, Oregon 97207 USA

e-mail: aslamk@pdx.edu

\section{U.S.Technical Staff}

\section{M.J. Shearer, C. L. Butenhoff, Z.Q. Xiong}

Department of Physics, Portland State University, P.O.Box 751,

Portland, Oregon 97207 USA

\section{R.A. Rasmussen}

OHSU Department of Science and Engineering, 20000 N.W.Walker Rd, Beaverton, Oregon 97006 USA

\section{PRC Collaborators}

\section{Li Xu}

National Climate Center, Chinese Meteorological Administration. Beijing, PRC

\section{Guangxi Xing}

Institute of Soil Science, Chinese Academy of Sciences, Nanjing, PRC

This research was supported by the Office of Science (BER),

\author{
U.S. Department of Energy
}




\section{Contents:}

Abstract

1. Introduction

1.1 Background and Rationale

1.2 Goals and Experiments

2. Results

2.1 Background and Context

2.2 Water Management

2.3 Fertilizer Applications

2.4 Temperature Effects

2.5 Effects of Plants

2.6 Inverse Relation Between Methane and Nitrous Oxide Emissions

3. Regional, Global and Temporal Extrapolations

3.1 Spatial Gridded Maps of Emissions

3.1.1 Methane Map

3.1.2 Nitrous Oxide Map

3.1.3 Carbon Equivalent

3.2 Decreasing Trends of Emissions

4. Conclusions

5. Personnel

6. Publications Resulting From the Project 


\begin{abstract}
:
This project produced detailed data on the processes that affect methane and nitrous oxide emissions from rice agriculture and their inter-relationships. It defines the shifting roles and potential future of these gases in causing global warming and the benefits and tradeoffs of reducing emissions.
\end{abstract}

The major results include:

1). Mechanisms and Processes Leading to Methane Emissions are Delineated.

Our experiments have tested the standard model of methane emissions from rice fields and found new results on the processes that control the flux. A mathematical mass balance model was used to unravel the production, oxidation and transport of methane from rice. The results suggested that when large amounts of organic matter are applied, the additional flux that is observed is due to both greater production and reduced oxidation of methane.

2). Methane Emissions From China Have Been Decreasing Over the Last Two Decades. We have calculated that methane emissions from rice fields have been falling in recent decades. This decrease is particularly large in China. While some of this is due to reduced area of rice agriculture, the bigger effect is from the reduction in the emission factor which is the annual amount of methane emitted per hectare of rice. The two most important changes that cause this decreasing emission from China are the reduced use of organic amendments which have been replaced by commercial nitrogen fertilizers, and the increased practice of intermittent flooding as greater demands are placed on water resources.

3). Global Methane Emissions Have Been Constant For More Than 20 Years.

While the concentrations of methane in the atmosphere have been leveling off in recent years, our studies show that this is caused by a near constant total global source of methane for the last 20 years or more. This is probably because as some anthropogenic sources have increased, others, such as the rice agriculture source, have fallen. Changes in natural emissions appear small.

4). Nitrous Oxide Emissions From Rice Fields Increase as Methane Emissions Drop. Inundated conditions favor anaerobic methane production with high emission rates and denitrification resulting in modest nitrous oxide emissions. Under drier conditions such as intermittent flooding, methane emissions fall and nitrous oxide emissions increase. Increased nitrogen fertilizer use increases nitrous oxide emissions and is usually accompanied by reduced organic matter applications which decreases methane emissions. These mechanisms cause a generally inverse relationship between methane and nitrous oxide emissions. Reduction of methane from rice agriculture to control global warming comes with tradeoffs with increased nitrous oxide emissions.

5). High Spatial Resolution Maps of Emissions Produced.

Maps of methane and nitrous oxide emissions at a resolution of $5 \mathrm{~min} \times 5$ min have been produced based on the composite results of this research. These maps are necessary for both scientific and policy uses. 


\section{Introduction:}

\subsection{Background and Rationale.}

Rice agriculture is an anthropogenic source of methane. Additionally, nitrous oxide is emitted when nitrogen-based fertilizers are used in agriculture. In recent years it has become evident that there has been a major increase in the use of nitrogen fertilizers in rice agriculture especially in China, thus making rice fields a potentially significant source of man-made nitrous oxide as well. Methane and nitrous oxide together are thought to be about $25 \%$ of the global warming that has occurred during the last century and are therefore included in treaties such as the Kyoto Protocol to limit global warming due to human activities.

The emissions of both these gases from most sources, including rice agriculture, are complicated by the processes that produce and consume them within the soils so that emissions are a residual between two similar numbers. This has led to a range of measured methane emissions from rice fields from almost no emissions to some $40 \mathrm{mg} / \mathrm{m}^{2} / \mathrm{hr}$ as a seasonal average. If all fields emitted at the upper limits of this range the global emissions from rice fields would be the single largest source of methane ( $170 \mathrm{Tg} / \mathrm{yr})$. Moreover, the agricultural practices that cause such a large range are changing on the global scale, and with that the emissions of methane from rice fields are also changing. These trends have a significant effect on what role methane will play in the future and to what extent we can use it to reduce global warming. Our research program was aimed at quantifying the effect of key agricultural trends of methane and nitrous oxide emissions from rice fields which suggest that the methane emissions are declining while nitrous oxide emissions rise. It is noteworthy that nitrous oxide is estimated to be 10 times more potent as a greenhouse gas than methane, so small increases can offset large reductions in methane emissions.

\subsection{Goals and Experiments:}

Specifically the goals of the project were (1) to obtain quantitative emission factors associated with the physical, chemical and biological processes that produce methane and nitrous oxide and lead to the widely differing emission rates observed in previous studies; (2) to produce a robust estimate of methane emissions from rice fields on a spatial grid so that regional, country and global emissions can be readily calculated. At the same time, we hoped to produce the first such results for nitrous oxide emissions on the same scales; (3) and to evaluate the changes of emissions from rice fields that have taken place over the last 20 - 30 years. We believe major changes have occurred and hence, estimates of emissions reported a decade or more ago even if they are accurate, are not representative of today. To accomplish these goals we carried out controlled greenhouse and field studies using classical experimental designs to quantitatively evaluate how key factors and their interactions with each other affect the emissions of methane. We developed and refined empirical models that explain the experimental results based on the known processes of production, oxidation, and transport. We use these models with existing agricultural and related data bases to extrapolate the emissions onto a spatial grid to delineate the global distributions of emissions and their trends.

The results we describe were obtained from controlled greenhouse experiments conducted at Portland State University in Portland, Oregon. We used a basic greenhouse which had modest 
control of temperature. Commercially available containers with surface area of $68 \mathrm{~cm} \times 45 \mathrm{~cm}$ were used to grow rice. These containers had an opening at the base that allowed us to drain the water according to the needs of the experiments. The field experiments were done in Nanjing, China in rice fields that were specially prepared with $4 \mathrm{~m} \times 4 \mathrm{~m}$ plots separated with concrete walkways. In both studies we used standard static chamber methods to collect three samples each time. The buildup of the gases is used to calculate the flux. In addition to the flux measurements, regular pore water measurements of dissolved methane and nitrous oxide were also taken at four depths to isolate zones of production and oxidation if they are separated. Finally, several other environmental variables were measured including plant growth dynamics, Eh and soil temperature at 4 depths.

The base experiments were in 4 sets: Controls, Organic matter applied, N-fertilizer applied and both organic matter and $\mathrm{N}$-fertilizer applied. Within each of these treatments there were two cases studied: continuously flooded and intermittently flooded as described earlier. This makes 8 sets. Triplicate plots (in the field) or pots (in the greenhouse) were used for each of these 8 sets making 24 plots or pots sampled in the field and the greenhouse respectively. This design was implemented in 2005 and 2006. In 2005 we also planted another 24 pots with the same treatments but with a commercial sterilized sandy loam soil rather than the more typical silt loam topsoil in the other pots. In 2005 the field experiments did not have continuously flooded plots. In the greenhouse experiments, the soils from 2005 were replaced with a sandy loam topsoil used for 2006 and 2007.

In addition to these base studies special experiments were done in 2006 and 2007. In 2006 we studied the effect of drainage length and frequency in the field and greenhouse experiments. Greenhouse experiments also included no plant plots and the effects of varying the amount of organic and nitrogen fertilizers applied. In 2007 we studied emissions in the field over the whole year which included crop rotations other than rice and also both a single crop and a double crop of rice.

\section{Results}

\subsection{Background and Context}

Methane emissions are affected by both agricultural practices and prevailing environmental conditions. Among the relevant environmental factors are the soil properties, rain (amount and timing), wind and temperature. Agricultural practices include factors such as rice cultivar, water management, fertilizer applications and crop rotations. While all of these have varying degrees of influence on the emissions, the agricultural practices, specifically water management and fertilizer use have emerged as possibly the most important contributors to the variability observed in the seasonally averaged emissions. We studied these two in detail in our experiments. When the fields are intermittently flooded the emissions are 2-4 times lower compared with the situation when the fields are continuously flooded. Similarly when organic amendments are used as fertilizer the emissions of methane are 2-4 times higher than when nitrogen fertilizers are applied. These two factors vary considerably in practice from region to region and country to country. Moreover, there are known systematic trends in these practices. In China for instance, organic amendments have been replaced by nitrogen fertilizers and intermittent flooding is more common now than before for various reasons including the 
demands on water use and the expansion of rice agriculture to new regions. Both these factors create a decreasing emission of methane and an increasing emission of nitrous oxide. Other factors also contribute to this inverse relationship as we will discuss later.

A feature of our experiments was to isolate the factors in the greenhouse experiments and test to see if similar results would be seen in the field. We therefore ran parallel experiments in the fields in Nanjing. The agreement of results between the greenhouse and field experiments is shown in Fig 1. It not only verifies the values of the measured parameters but it also gives us confidence that the results from the greenhouse are widely applicable and suitable for extrapolation. Other figures also show this agreement in more detail.

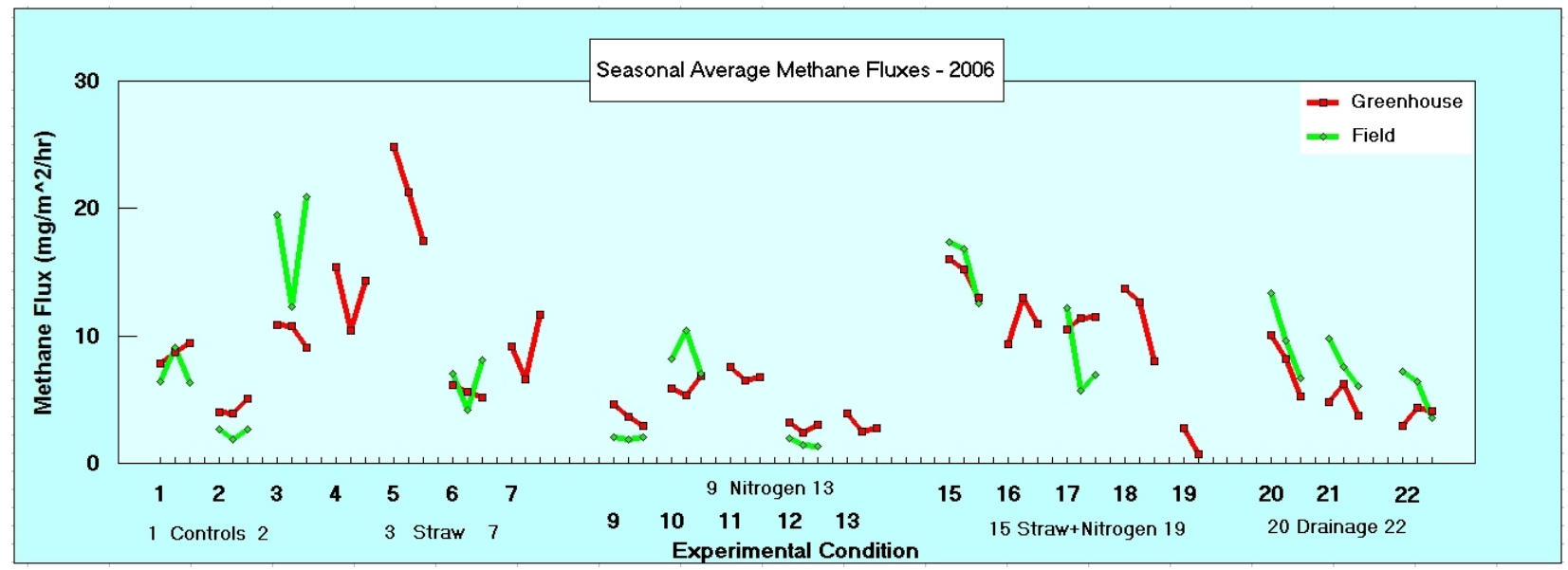

Figure 1 - The agreement between greenhouse and field experiments. Results shown are the seasonal average emission rates of methane from various controlled experimental plots. The quantitative calculation of the effects of water management and fertilizer found in the greenhouse experiments in Oregon are seen to be closely replicated in the fields of Nanjing. The three points for each experiment are the three replicates and show the intra-factor variability. Key: The experiments are classified by water management $=\mathrm{W}$ and fertilization $\mathrm{S}$ (for straw or organic fertilizer) and $\mathrm{N}$ (for nitrogen fertilizer). W0 $=$ Continuous flooding, $\mathrm{W} 2=$ intermittent flooding. $\mathrm{Sx}=$ Straw added where $\mathrm{x}=0,1,2,3$ depending on no straw to various equal increment increasing amounts, $\mathrm{Nx}=$ nitrogen fertilizer added with $\mathrm{x}=0,1,2,3$ as with straw. The last three experiments are for drainage conditions Dx where $\mathrm{x}=1,2,3$ showing increasing drainage. $1=\mathrm{W} 0 \mathrm{~S} 0 \mathrm{~N} 0$; 2=W2S0N0; $3=\mathrm{W} 0 \mathrm{~S} 1 \mathrm{~N} 0 ; 4=\mathrm{W} 0 \mathrm{~S} 2 \mathrm{~N} 0 ; 5=\mathrm{W} 0 \mathrm{~S} 3 \mathrm{~N} 0 ; 6=\mathrm{W} 2 \mathrm{~S} 1 \mathrm{~N} 0 ; 7=$ W2S3N0; 9=W2S0N1;10=W0S0N2;11=W0S0N3;12=W2S0N2;13=W2S0N3; $15=\mathrm{W} 0 \mathrm{~S} 2 \mathrm{~N} 1 ; 16=\mathrm{W} 2 \mathrm{~S} 2 \mathrm{~N} 1 ; 17=\mathrm{W} 0 \mathrm{~S} 1 \mathrm{~N} 2 \mathrm{~S} 1 ; 18=\mathrm{W} 0 \mathrm{~S} 1 \mathrm{~N} 2 \mathrm{~S} 0 ; 19=\mathrm{W} 0 \mathrm{~S} 1 \mathrm{~N} 2 \mathrm{No}$ Plant Plot; 20=W2S1N2D1; 21=W2S1N2D2; 22=W2S1N2D3. 


\subsection{Water Management}

Water management in the rice fields can essentially be classified into two broad categories: Continuously flooded and intermittently flooded. In continuous flooding water is kept in the fields for most of the growing season usually by irrigation. Water is drained a short time before harvest and possibly for fertilizer application at some time in the crop cycle. Intermittent flooding, if managed, usually involves mid season drainage for a week or more, and early drainage before harvest or drying when the crop is well established. The later drying may be due to evaporation if fields are not re-flooded. Another type of intermittent flooding is rain fed rice agriculture. Rain fed fields can be continuously flooded depending on the location and local climate. Alternatively rain fed rice can have the features of intermittent flooding. We investigated the effects of continuous and managed intermittent flooding in depth and have run experiments that provide the required information on intermittent rain-fed rice agriculture. The results can be readily integrated into our extrapolation models to estimate emissions under rain fed conditions. As mentioned above, continuous flooding results in a greater seasonal average methane emission than intermittent flooding. Our research has verified and validated this observation, but more importantly we have quantified the relationship between the emissions under these two disparate water management practices.

Experiments of all 3 years involved both types of water management. In 2005 the experiments were set up for the first time. The main experiments were conducted under the proposed factorial experimental design (Snedecor and Cochran, 1989). The variables were water management, fertilizer use and soil types. Some of the problems that arose during the first year were corrected and the most detailed experiments were done in 2006. In 2007 we conducted experiments to fill in the gaps in our understanding and in particular looked at the whole year emissions as well as the effects of crop rotations. The purpose of the whole year experiments is different for methane and nitrous oxide. There is no methane emission if the fields are not flooded as when they are fallow or are planted with other crops. The nature of the crops that precede the planting of rice does affect the supply of decomposable organic matter in the rice fields at the beginning of the crop cycle. This in turn has a major affect on the methane emissions during the rice growing season. For nitrous oxide the emissions that come from nitrogen fertilizer applications can continue well beyond the harvest, and may be greater in aggregate after the rice harvest than during the growing season. We tested and quantified these causes of emissions in the last set of experiments that were built on the results from the two years before. With this background in mind, we will describe our results from the experiments next and then connect them to regional and global emissions.

In our experiments we had 24 individual plots as previously described $=4$ fertilizer conditions $\times$ 2 water management conditions $\times 3$ replicates for each condition. 4 fertilizer conditions $=$ No fertilizers applied, only nitrogen applied, only straw added and both nitrogen and straw added. Water management $=$ continuous flooding and managed intermittent flooding. The standard rate of application of the fertilizers is about 3 tons/hectare equivalent of straw and $220 \mathrm{~kg} / \mathrm{h}$ of Nfertilizer applied as urea or another common fertilizer. Controls received a base P-K fertilizer to grow the crops while the experimental groups received additional amounts as discussed.

In Fig 2 we see first the similar effect of water management both in the field and in the greenhouse based on the experiments conducted in 2006 which were designed to study the effects 
of water management. In these figures we have taken the average of all cases when the plots are continuously flooded and the average when they are intermittently flooded. So these graphs average over the other variables such as the effects of fertilizer types and amounts. For both the 2005 and 2006 greenhouse experiments, the results showed about $12 \mathrm{mg} / \mathrm{m}^{2} / \mathrm{h}$ average emissions from the flooded pots and $6 \mathrm{mg} / \mathrm{m}^{2} / \mathrm{hr}$ from the intermittently flooded plots averaged over all conditions as in Fig 1. Results from the fields experiments showed emissions of $12 \mathrm{mg} / \mathrm{m}^{2} / \mathrm{hr}$ from the flooded fields and about $4 \mathrm{mg} / \mathrm{m}^{2} / \mathrm{hr}$ from the intermittently flooded fields, or a factor of 3. The response in the greenhouse can be suppressed due to the cooler growing conditions as we will discuss further in section 2.4 .
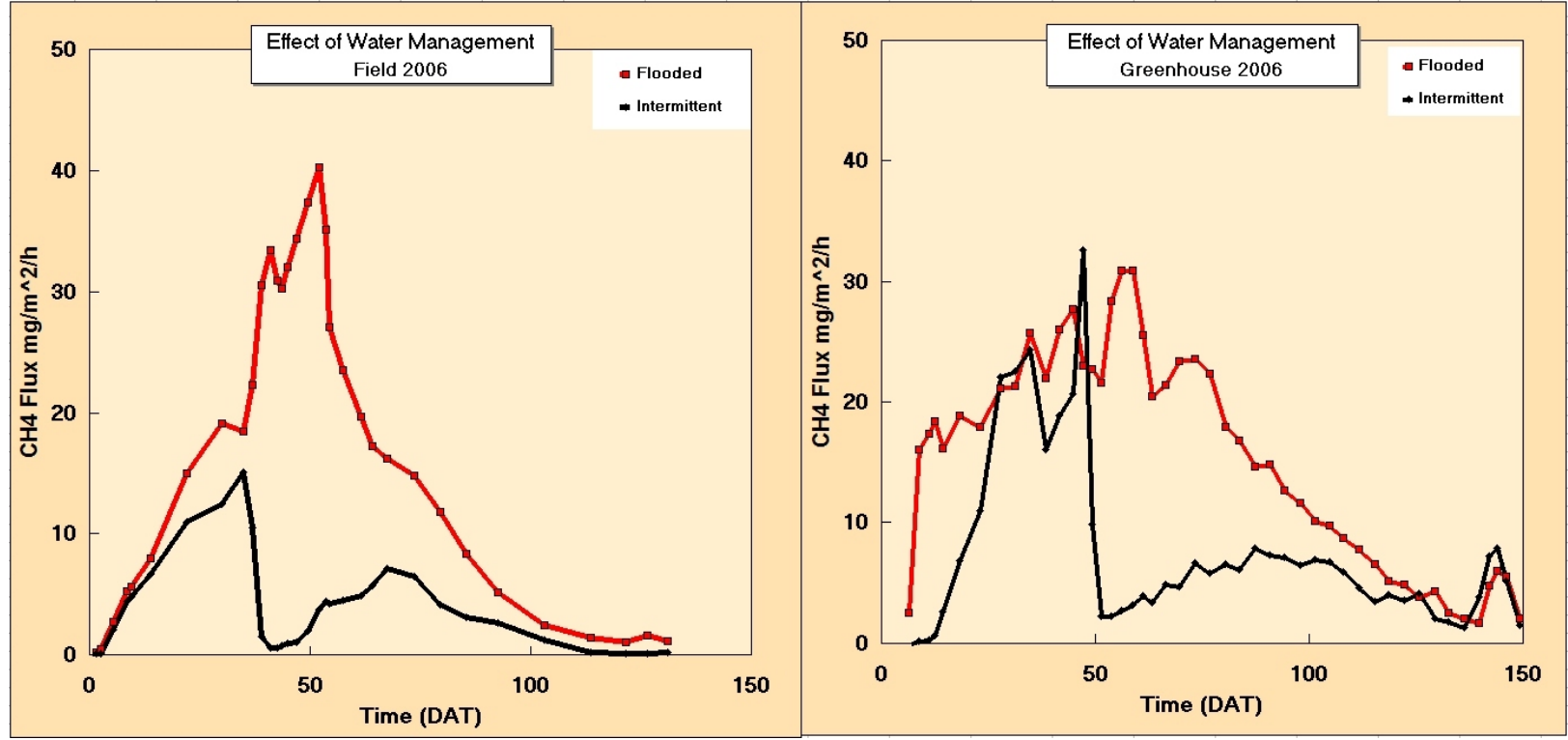

Figure 2 - The effect of water management on methane emissions from rice fields. We have averaged the effect of all other variables including fertilizer use to isolate the average effect of water management on the emissions. The figures show that after midseason drainage in the intermittent flooding condition, methane emissions fall and do not recover later even when water is present. Similar results were found for each year. DAT $=$ Days after transplanting.

In separate experiments we also studied the effects of drainage length and frequency. In greenhouse experiments, we used three plots each that were drained in mid season for 5 days, 10 days and 15 days, where 10 days is the typical period. Fig 3 shows the remarkably consistent results establishing that longer drainage leads to lower emissions. The emission rates were 4, 5 and $8 \mathrm{mg} / \mathrm{m}^{2} / \mathrm{hr}$ averaged over the growing season for the drainage periods of 5,10 and 15 days respectively. In these plots we applied both straw and nitrogen fertilizer, but the same amounts were added to all 9 pots ( 3 each for the 3 conditions). In a similar study conducted in the field, we found average emission rates of 10,8 and $6 \mathrm{mg} / \mathrm{m}^{2} / \mathrm{hr}$ for drainage periods of 6 days, 14 days and three drain flood cycles of 14 days each ( 7 days flooded, 7 days drained). 


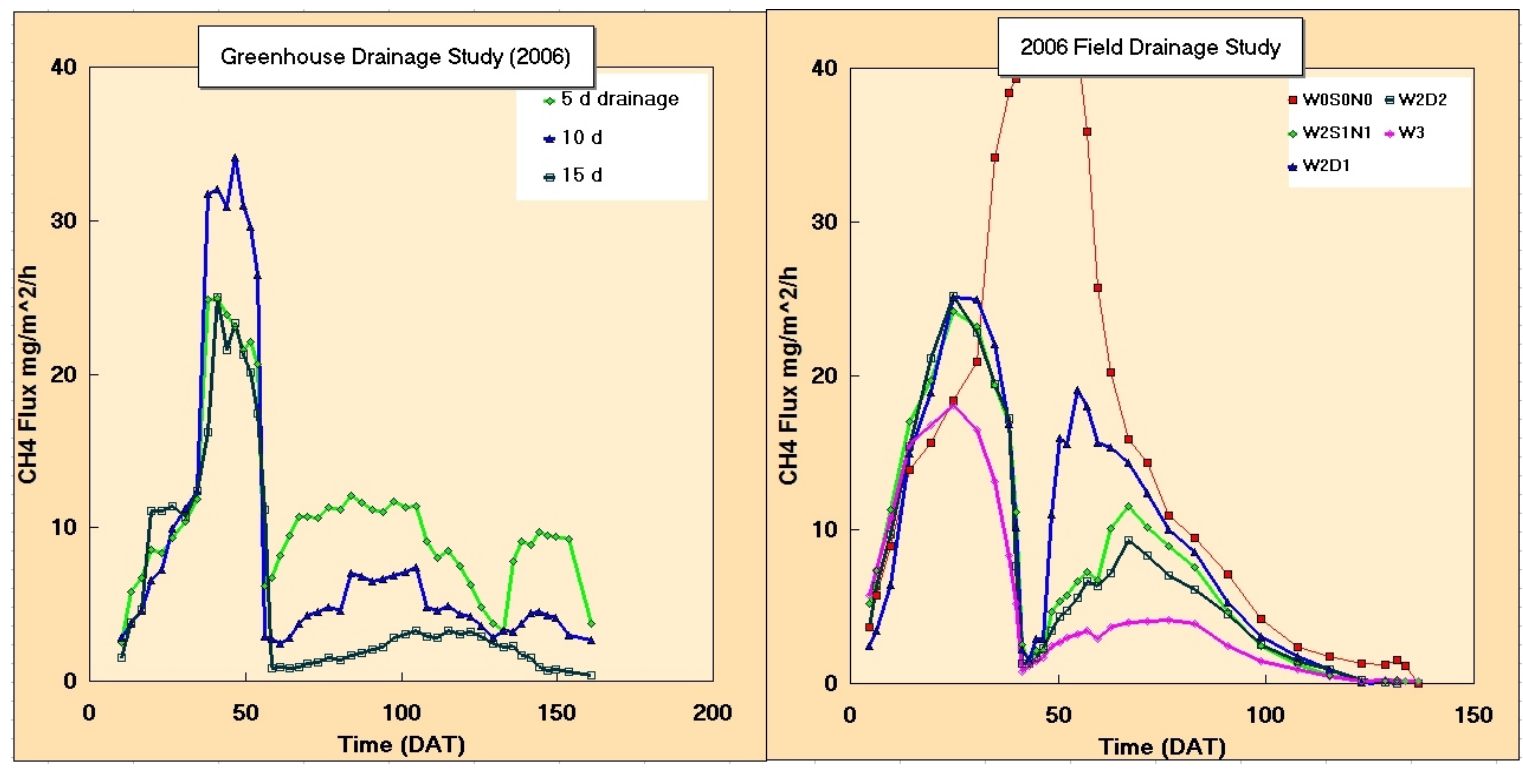

Fig 3: The effect of water drainage practices on methane emissions from rice fields. This figure complements Fig 2 and shows the results of specific experiments with drainage conducted both in the field (Nanjing, China) and in the greenhouse (Portland, Oregon). The greenhouse experiments show the effect of the duration of drainage on emissions. Short drainage has little effect but, once the drainage period extends to 5 days or longer, the effect increases. In the field study we have included the figure for continuous flooding for comparison. The results are similar to those found in the greenhouse. It is also noteworthy that the emissions were similar from these plots before the drainage. DAT $=$ Days after transplanting.

The results for nitrous oxide are more variable and complex but reveal significant information about the role of rice fields on emissions. Nitrous oxide is produced naturally in soils as part of the global nitrogen cycle. For agricultural soils, the emissions of nitrous oxide is increased by the application of nitrogenenous fertilizers that supply additional nitrogen for the cycle. Most of the nitrous oxide emitted from soils is produced by microbial nitrification and denitrification processes. Microorganisms and fungi can produce $\mathrm{N}_{2} \mathrm{O}$ by other processes as well, but the role of such processes in agricultural systems is not known.

In denitrification processes, nitrate or nitrite is reduced to $\mathrm{NO}, \mathrm{N}_{2} \mathrm{O}$ or $\mathrm{N}_{2}$. Nitrous oxide is also consumed in such processes and serves as an intermediary for the production of $\mathrm{N}_{2}$. Under such circumstances, when $\mathrm{N}_{2} \mathrm{O}$ is both being produced and removed, the amount that is released to the atmosphere can be extremely variable as is the case for emissions from rice fields. Denitrification processes may be most important for the production of $\mathrm{N}_{2} \mathrm{O}$ in rice fields during the growing season when the fields are inundated for some or most of the time since nitrification requires oxygen which is not present in the inundated soils. In nitrification processes, ammonium is oxidized to nitrate releasing some nitrogen as $\mathrm{NO}$ and $\mathrm{N}_{2} \mathrm{O}$ to the atmosphere. In rice fields, as in other agricultural systems, the nitrification and denitrification cycles can be coupled leading to a wide range of $\mathrm{N}_{2} \mathrm{O}$ emissions. This can happen if nitrate from nitrification processes diffuses to anaerobic sites where denitrification can take place as may happen in intermittently flooded rice fields, or at times when the fields are not inundated with water as after harvest (see e.g., Zumft 
and Kroneck, 1990).

The results found in the field and the greenhouse were qualitatively consistent but the magnitudes of the responses were quite different. In the field experiments intermittent flooding cases produced about $30 \%$ more nitrous oxide emissions, while in the greenhouse experiments there was about twice as much nitrous oxide emitted from intermittently flooded plots as from the continuously flooded pots. The absolute emission rates were also higher in the greenhouse experiments. Research is currently underway to determine the possible causes for these differences. We note that water management is one of the several factors that causes opposite effects for the emissions of methane and nitrous oxide as we will discuss in more detail in section 2.5 .

\subsection{Fertilizer Applications}

It stands to reason that adding organic amendments to the rice fields will lead to a greater methane production and adding nitrogen fertilizers will produce more nitrous oxide. The quantitative relationships between the use of fertilizers and the various factors that affect emissions is not well known or understood. In this study we have made this connection.

Two types of soil amendments were applied: Nitrogen based fertilizer as urea, and rice or wheat straw as organic manure. The amounts and timing were varied to determine the effect on the emissions. The controls had a base amount of fertilizer needed to grow the rice. After that additional fertilizers were applied at the rates typically found in the Nanjing area where the field experiments were conducted. These rates were $220 \mathrm{kgN} / \mathrm{ha}$ for nitrogen and $3 \mathrm{mtons} / \mathrm{ha}$ for the straw. The amounts of $\mathrm{N}$-fertilizers were taken as 100 and $300 \mathrm{kgN} / \mathrm{ha}$ in addition to the typical case and 6 and 9 mtons/ha for the straw. The straw is a convenient form of organic fertilizer and represents crop residues that are often plowed into the soil. Other forms of organic amendments are also used in the field including sludge from biogas pits and compost. How much the emissions are affected by the different types of organic fertilizers was not studied and it is expected that the unifying factor is readily decomposable organic matter in each of these types of organic amendments per kilogram. Decomposition that produced methane must occur during the inundated period otherwise methane will not be produced although the decomposition continues, as during fallow periods or when other crops are planted either before or after the rice crop. Similarly N-fertilizers can also be applied in different forms and may affect emissions differently.

The results can be seen in Fig 4. Here we have averaged the cases across all other variables except the organic amendment. Therefore, each graph includes both continuously and intermittently flooded conditions as well as application of nitrogen fertilizers or not. It is apparent from both the field and greenhouse studies that the addition of organic amendments leads to significantly greater methane emissions. It is also evident that there is an early peak in the emissions as the straw decomposes. The effect of adding straw leads to a factor of 3-4 higher emissions in the field studies and about a factor of 2 higher in the greenhouse experiments. We believe this difference is caused by the substantially lower temperatures in the greenhouse compared with Nanjing, especially during the first 60 days when the factors that cause emissions are favored. We will discuss this further in Sec. 2.4. Further quantification of this effect is seen in the experiments when straw applications were varied over $0,3,6$ and $9 \mathrm{mtons} / \mathrm{ha}$. The results 
are shown with remarkable clarity in Fig 5.
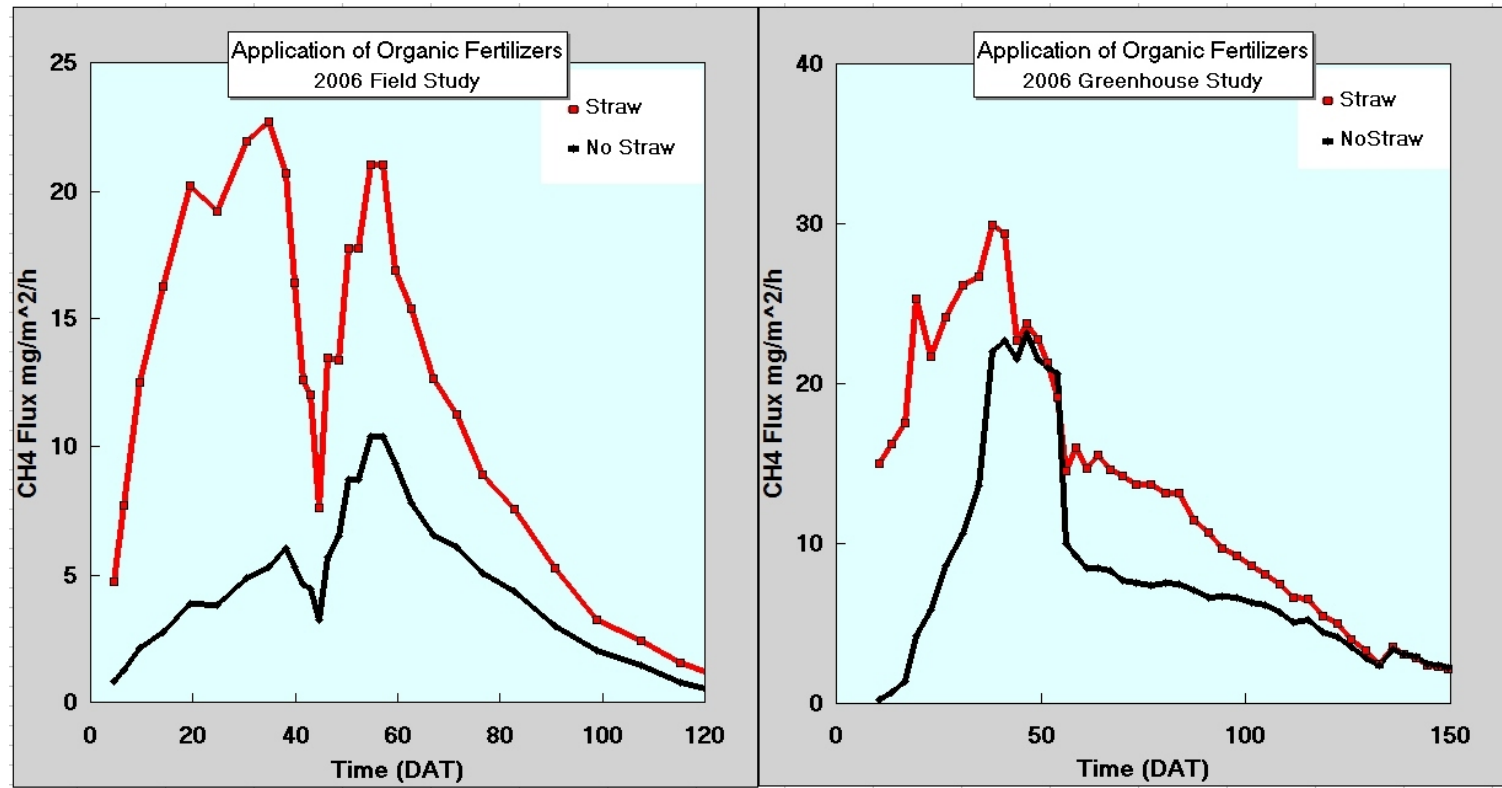

Fig 4: The effect of organic fertilizers on methane emissions from rice fields. Variable other than organic fertilizer applications have been averaged, including the effect of water management. What remains is the effect of organic fertilizer applications averaged over prevalent conditions. It is evident that the methane flux is greatly increased when organic amendments are added. Various factors affect the relationship shown here as discussed in the text (see also Fig 5). DAT = Days after transplanting.
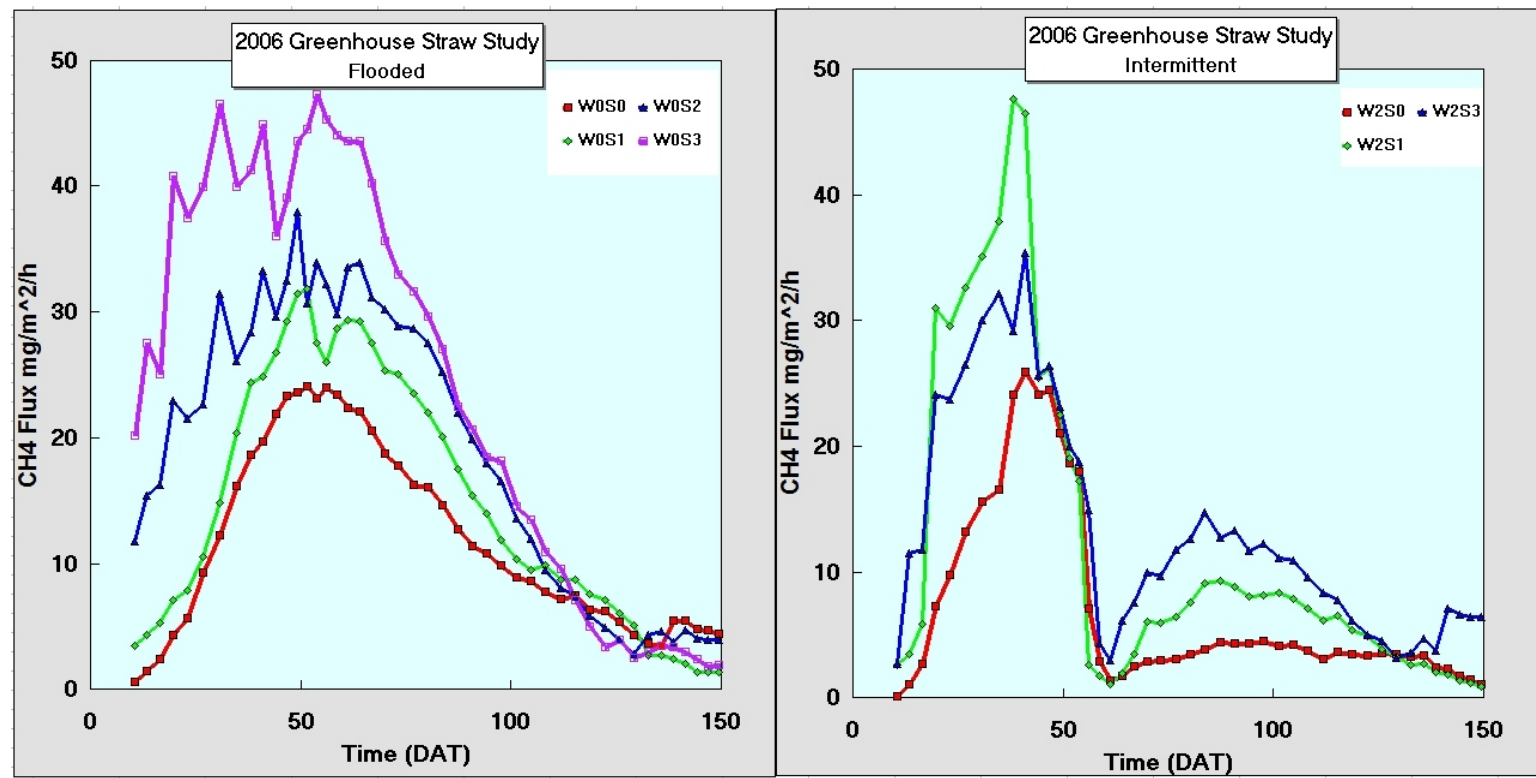

Fig 5: The effect of organic fertilizer applications on methane emissions from rice fields. These figures show the effect of detailed experiments conducted in the greenhouse for both flooded and intermittently flooded conditions. Adding organic fertilizers causes emissions to increase linearly. The details are in the text. DAT $=$ Days after transplanting. 
A proportional relationship exists between the amount of straw applied and the methane emissions. To quantify this relationship we adopted a model formula:

$F=F_{o} e^{\alpha(T) C} e^{\beta N}$

$\alpha=\alpha_{0}+\rho_{1} \mathrm{~T}+\rho_{2} \mathrm{~T}^{2}$

$\alpha_{0}=0.021 ; \rho_{1}=-0.0021 ; \rho_{2}=0.0000551$ and $\beta \approx 0.016$ and -0.036 under continuously and intermittently flooded conditions, respectively. The coefficients $\alpha$ and $\beta$ are determined from the experiments and have units $\mathrm{m}^{2} / \mathrm{g} \mathrm{C}$ and $\mathrm{m}^{2} / \mathrm{g} \mathrm{N}$ respectively. $\mathrm{C}$ and $\mathrm{N}$ are the rates of organic dry matter and nitrogen-based fertilizer applied per unit area. $\mathrm{F}_{\mathrm{o}}$ is the base flux with no additional fertilizer applied. $\mathrm{F}_{\mathrm{o}}=7.3$ and $2.4 \mathrm{mg} \mathrm{CH}_{4} \mathrm{~m}^{-2} \mathrm{hr}^{-1}$ for continuously and intermittently flooded conditions respectively.

We also derive the coefficients of the model for $\mathrm{N}_{2} \mathrm{O}$ based on our experiments. In this case $\alpha=$ $-0.005,-0.002 \mathrm{~m}^{2} / \mathrm{g} \mathrm{C} ; \beta=0.0135,0.0573 \mathrm{~m}^{2} / \mathrm{g} \mathrm{N} ; \mathrm{F}_{\mathrm{o}}=6.3,8.3 \mu \mathrm{g} \mathrm{N}_{2} \mathrm{O} \mathrm{m}^{-2} \mathrm{hr}^{-1}$ for continuously and intermittently flooded conditions respectively. We found no statistically significant temperature dependence of $\alpha$ for $\mathrm{N}_{2} \mathrm{O}$. We will use these relationships to extrapolate our quantitative results to emissions from China and the world in Section 3.

Our experiments were designed to directly measure the $\alpha$ and $\beta$ as was discussed earlier. Triplicate plots included treatments of controls, organic matter (chopped straw) only, N-fertilizer only and both organic and N-fertilizers.

\subsection{Temperature Effects}

As the soil temperature increases methane and nitrous oxide emissions are observed to increase as well. The present set of experiments was not designed to systematically study this effect but it was observed and had to be taken into account to integrate the field and greenhouse experiments. The greenhouse was of modest quality and did not allow for a precise control of temperature. This caused the average soil temperature in the greenhouse to be lower than in the Nanjing fields, which are in one of the hotter environments where rice is grown. Curiously, such an effect was not observed for nitrous oxide.

Temperature affects all the three major processes that cause methane emissions from rice fields, namely production, oxidation and transport. The rate at which bacteria can degrade organic matter is a chain of several steps and each step has a temperature dependence, thus causing variability in the system. Similarly, methanotrophic bacteria that oxidize methane are also stimulated by increasing temperature. But since they remove methane, their increase with temperature offsets the effect of the higher production by methanogenic bacteria. This causes the temperature response to be greatly moderated. Within these competing processes, the transport also plays an important role. If the transport speeds up with increasing temperature it favors a greater emission because the methane produced does not spend enough time near the methanotrophs to be effectively oxidized. This conceptual understanding has been put into a theoretical model which is being used to investigate the relationship rigorously. Based on our results a Q10 of 3.7 is calculated. We are currently conducting experiments to verify the validity 
of this result.

\subsection{Role of Plants in Emissions}

Our experiments have clarified and quantified the important role of rice plants in the emissions of methane and nitrous oxide. In the control group when the pots had no plants, there were almost no methane emissions for either continuously or intermittently flooded conditions $(<1$ $\mathrm{mg} / \mathrm{m}^{2} / \mathrm{hr}$ ). For the same conditions 4 and $9 \mathrm{mg} / \mathrm{m}^{2} / \mathrm{hr}$ average emissions were found when plants were present. When straw was added or when nitrogen fertilizer and straw were added, the pots without plants produced much more methane than the control conditions without plants (1-6 $\mathrm{mg} / \mathrm{m}^{2} / \mathrm{hr}$ ). At the same time the pots with plants under these same conditions produced many times more methane than pots without plants $\left(6-20 \mathrm{mg} / \mathrm{m}^{2} / \mathrm{hr}\right)$. The plants play a dual role in that root exudates and dying roots add to the organic pool that makes methane and the aerenchyma in the rice plants, like many other wetland plants, create a fast transport conduit for the emission of methane. Fig 6 illustrates the effect. These data add much new information on how methane is produced and emitted from the soil not only in rice agriculture but also in wetlands. Work is continuing on incorporating the new information into a consistent model of methane emissions.
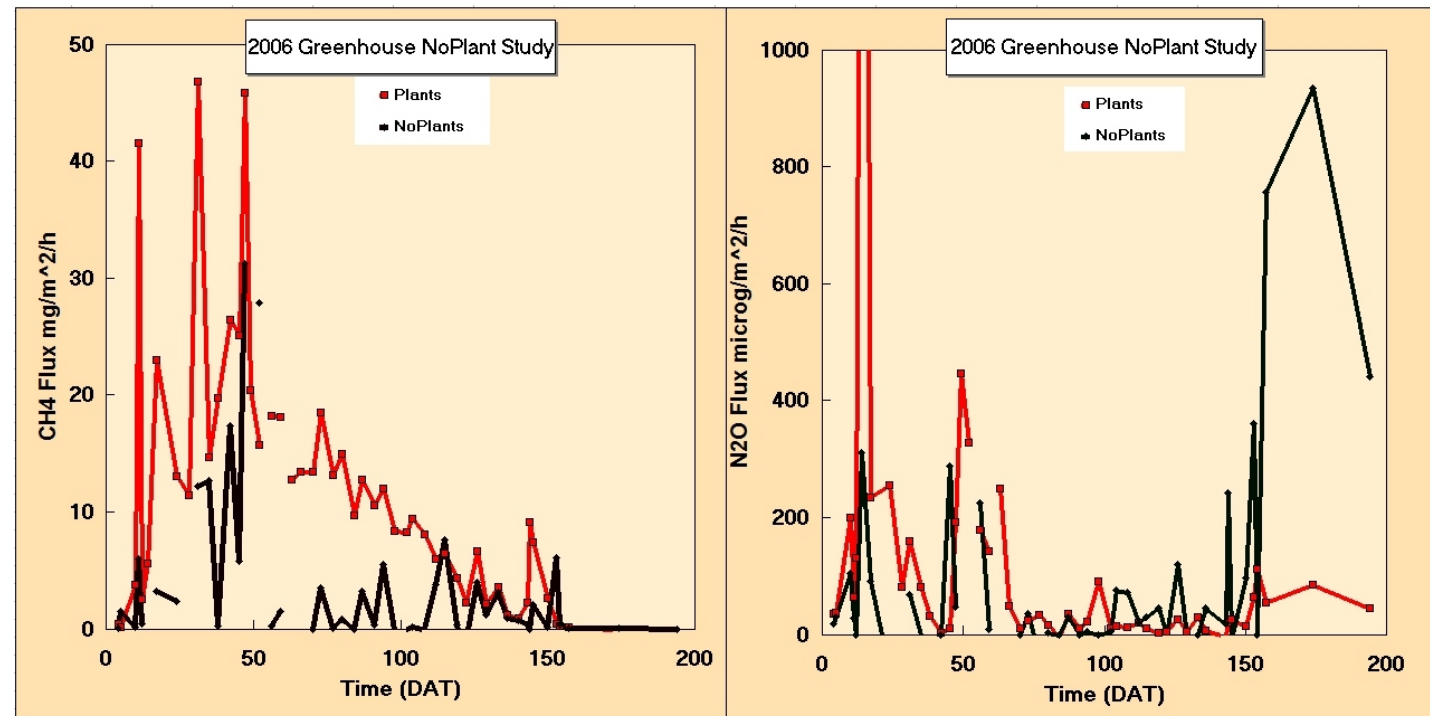

Fig 6: The role of plants in the emission of methane and nitrous oxide from rice fields. In the results shown here we compare the emissions from plots with no plants and those with plants. Aside from the plants the pots were treated identically. It is evident that plants are a crucial element in the emission of methane, which includes enhanced transport and the supply of organic matter in the root zone. For nitrous oxide the relationship is less clear. DAT $=$ Days after transplanting.

\subsection{Inverse Relation Between Methane and Nitrous Oxide Emissions}

There are a number of mechanisms that create an inverse relationship between methane and nitrous oxide emissions under many conditions and especially from rice agriculture. This relationship is particularly important for strategies to control greenhouse gas emissions to abate 
global warming. The concomitant increase of nitrous oxide can offset some of the gains of reducing methane emissions. At this time the balance of this effect is unknown on a global scale and is the subject of continuing research.

The mechanisms driving this relationship are both intrinsically environmental as well as from shifts in agricultural practices. Under inundated conditions, methane is produced by anaerobic processes while nitrous oxide comes mostly from denitrification while nitrification is virtually shut off. The source of nitrous oxide under inundated conditions presumed to be denitrification, is observed to be rather low. Additionally, in our experiments we found that when excess organic material is applied, it suppresses nitrous oxide emissions while increasing methane emissions even under inundated conditions. Under drained conditions, methane emissions shut down and nitrification picks up resulting in nitrous oxide emissions. The combination of these two phenomena results in the inverse relationship along with other mechanisms that work in the same direction. This feature is shown in Fig. 7 below. As we have discussed, a shift in agricultural practices away from continuously flooded rice agriculture will therefore favor a greater emission of nitrous oxide and lower emissions of methane. The second mechanism is the shift in agricultural use of manure and organic fertilizers in favor of nitrogen fertilizers. Based on the results we have already discussed the reader will recognize that there would be a significant increase of nitrous oxide and suppression of methane from this practice because of the direct relationship between organic fertilizer applications and methane emissions and between nitrogen fertilizer applications and nitrous oxide emissions.

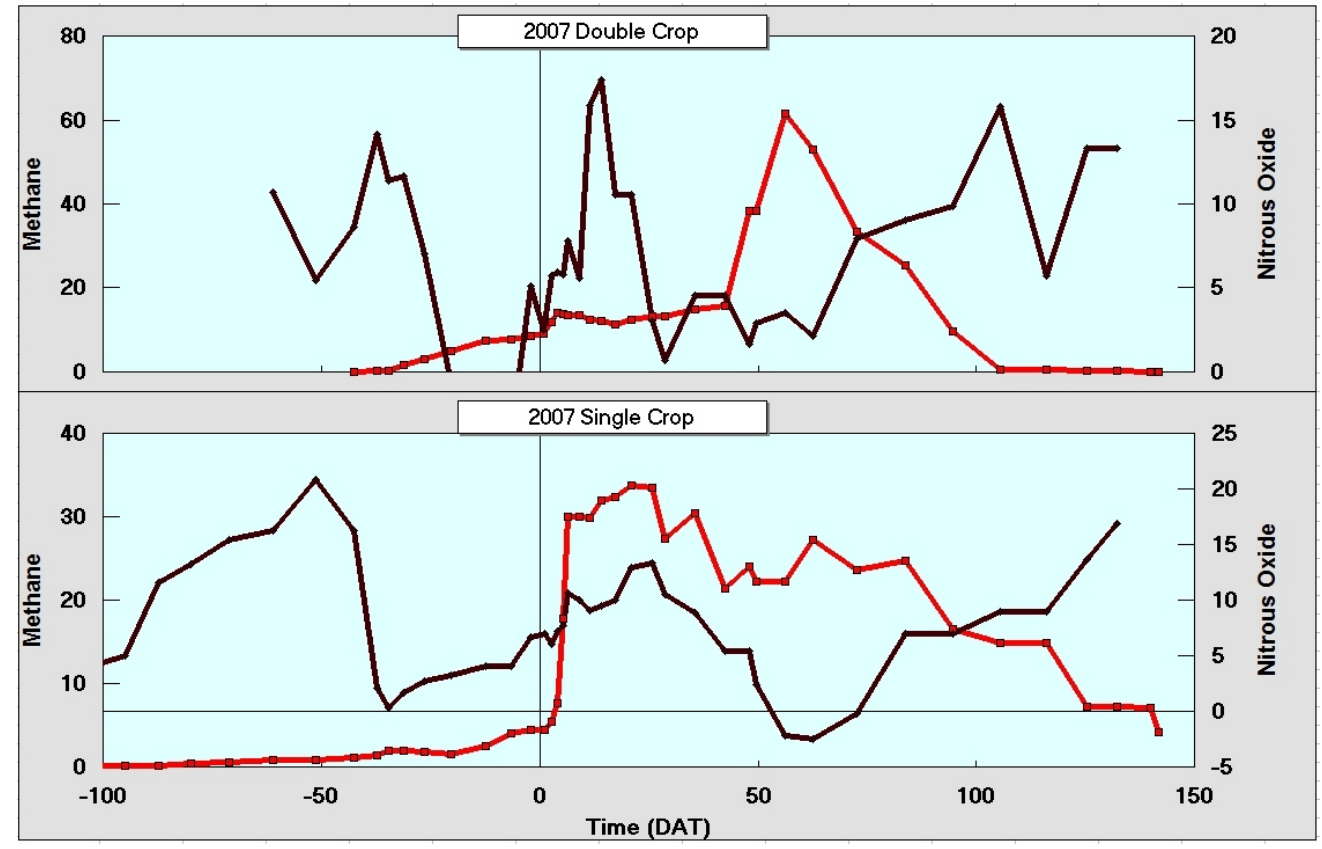

Fig 7: The inverse relationship between methane and nitrous oxide emissions. Several factors contribute to this inverse relationship as discussed in the text. These include both fertilizer and water management effects. The results here are from the whole year studies to look at the emissions of methane and nitrous oxide when the fields are fallow or have crops other than rice. When the rice crop is not present, nitrous oxide emissions are generally high, while there is virtually no methane emissions during this time (see also Fig 8). DAT = Days after transplanting. 


\section{Regional, Global and Temporal Extrapolations}

\subsection{Spatial Gridded Maps of Emissions}

As we have discussed, through our greenhouse and field studies, we have identified the factors that most influence methane and nitrous oxide fluxes from rice paddies and quantified the functional relationship linking the fluxes to the factors. Our next goal is to apply our empirical model to national and global scales and create gridded spatial inventories of both methane and nitrous oxide emissions. Few global inventories of paddy emissions exist, and the emissions of those that do have not yet converged at either national or global levels, indicating the continued need for further study and refinement. Our inventories move us closer to this goal and are constructed using novel methods and data sets including the following innovations:

1. We used an empirical model that we derived from controlled greenhouse experiments and validated by measurements in the field. Though the model is simple in structure, it is complete in the sense it includes the major variables that control methane and nitrous emissions from the paddy environments. Fluxes calculated from the model are based on agricultural and environmental factors that can be reasonably acquired at appropriate spatial scales, unlike existing models that require detailed inputs that do not exist at global scales.

2. Our model includes the complex interaction between nitrogen fertilizer and methane emissions. Our experimental results indicate that increased rates of nitrogen application increase methane emissions in continuously-flooded paddies, but decrease methane emissions otherwise. To our knowledge, the sensitivity of methane to $\mathrm{N}$-fertilization has not been included in any other methane inventory.

3. We used orbital remote-sensing of vegetation to estimate application rates of crop biomass to paddy fields, a major source of organic-carbon material and driver of methane flux. This method provided global coverage of this factor at high spatial resolution.

We constructed underlying data layers as model input for the following factors: rice location and area, crop calendar (i.e. planting and harvesting dates), soil temperature, organic carbon and nitrogen inputs, and water management (inundation). A brief description of each follows.

- Rice production locations and areas are taken from Monfreda et al. (2008). Monfreda et al. distribute national and subnational rice cropping areas on a $5 \min \times 5 \min (\sim 10 \mathrm{~km} \times$ $10 \mathrm{~km}$ ) grid based on a global cropland base map (Ramankutty et al., 2008).

- Rice cropping seasons and planting and harvesting dates are taken from Matthews et al. (1991). Matthews et al. compiled rice crop calendars from the UN's Food and Agriculture Organization, the International Rice Research Institute's World Rice Statistics, and other national and subnational agricultural statistical handbooks and atlases.

- Soil temperatures were derived from re-analysis of surface air temperature from the National Weather Service's National Center for Environmental Prediction. Daily air 
temperatures were averaged over the 60-day period following rice-planting dates as past work indicates this average is the best indicator of flux. Surface air temperatures were converted to soil temperatures using relations established from field measurements.

- To simulate the addition of organic carbon to paddy fields we considered the largest sources of organic carbon, including straw, crop roots, stubble, and farm animal manure. We used leaf area index products from the satellite-based MODIS instrument to estimate crop standing biomass. We distributed the mass across plant components and assumed that roots, stubble, and some fraction $f$ of the straw are returned to the paddy field. Values of $f$ were taken from survey samples as well as farm animal manure application rates (Huang et al., 2006).

- Nitrogen application rates were determined from the United Nation's Food and Agriculture Organization's FertiStat database (http://www.fao.org/ag/agl/fertistat/) and from Chinese agricultural statistical databases available from the University of New Hampshire's EOS-WEBSTER site (http://eos-webster.sr.unh.edu/home.jsp).

- The percentage of paddy area under continuous flooding and intermittent drainage management was provided by Yan et al. (2009) at the national level.

These data layers were combined using our flux model and global methane and nitrous oxide maps were created (Figs. 8 and 9 , respectively).

\subsubsection{Methane Maps}

We estimate global annual methane emissions from rice paddies are $49 \mathrm{Tg} \mathrm{CH}_{4} \mathrm{y}^{-1}$, which falls roughly in the middle of the range of current estimates, $\sim 25$ to $100 \mathrm{Tg} \mathrm{CH}_{4} \mathrm{y}^{-1}$ (Denman et al., 2007. Though rice agriculture is widespread globally, emissions are concentrated in south and southeast Asia where rice is a staple crop and provides a large percentage of the daily calories. We estimate that this region is responsible for about $90 \%$ of the world's emissions, with major concentrations in India, China, Vietnam, and Bangladesh (Table 1), along major rivers and deltas.

Noteworthy and novel to our inventory is the distribution of emissions between countries. While conventional thinking views China as the world's largest emitter of methane from rice paddies, our findings challenge this notion. Instead we find that India leads the world, and its emissions are significantly higher than China's (Table 1). While this finding may be surprising, it is consistent with known changes to rice management that have taken place in China over the past couple decades. In the early 1980s Chinese farmers realized that intermittent draining of their rice fields midway through the rice season increased grain yields. As a result, only about $20 \%$ of paddy fields are now left flooded through the rice season (Yan et al., 2009; Li et al., 2002), which in turn decreases seasonal methane emissions. In past work we estimated that Chinese methane emissions from paddies decreased by about 12-17 $\mathrm{Tg} \mathrm{CH}_{4} \mathrm{y}^{-1}$ since 1980 (Khalil and Shearer, 2006; see next section) and our current results support this reduction. If we increase the fraction of continuously-flooded fields to $100 \%$ within China, which is representative of 1980 
management, our model predicts that emissions increase by $11 \mathrm{Tg} \mathrm{CH}_{4} \mathrm{y}^{-1}$.

Table 1. Annual methane and nitrous oxide emissions from South and Southeast Asian rice paddies

\begin{tabular}{lcccc}
\hline & $\begin{array}{c}\text { Paddy area } \\
\left(10^{6} \mathrm{ha}\right)\end{array}$ & $\begin{array}{c}\text { Methane } \\
\left(\mathrm{Tg} \mathrm{CH}_{4} \mathrm{y}^{-1}\right)\end{array}$ & $\begin{array}{c}\text { Nitrous oxide } \\
\left(\mathrm{Gg} \mathrm{N}_{2} \mathrm{O} \mathrm{y}^{-1}\right)\end{array}$ & $\begin{array}{c}\text { Carbon equiv. } \\
\left(\mathrm{Tg} \mathrm{CO}_{2} \mathrm{y}^{-1}\right)\end{array}$ \\
\hline Bangladesh & 11.2 & 3.4 & 2.0 & 72 \\
Bhutan & 0.013 & 0.0035 & 0.0037 & - \\
Brunei & 0.001 & 0.0027 & -- & -- \\
Burma & 6.19 & 2.7 & 1.1 & 57 \\
Cambodia & 1.90 & 0.93 & 0.41 & 20 \\
China & 30.7 & 5.1 & 23 & 114 \\
India & 43.5 & 15 & 8.3 & 318 \\
Indonesia & 11.8 & 3.4 & 1.9 & 72 \\
Japan & 1.80 & 0.28 & 0.43 & 6 \\
Korea, N & 0.555 & 0.061 & 0.13 & 1 \\
Korea, S & 1.13 & 0.16 & 0.24 & 3 \\
Laos & 1.29 & 0.44 & 0.17 & 6 \\
Malaysia & 0.828 & 0.28 & 0.073 & 13 \\
Nepal & 1.74 & 0.61 & 0.52 & 21 \\
Pakistan & 2.59 & 1.0 & 0.60 & 34 \\
Papua New Guinea & --- & -- & -- & -- \\
Philippines & 4.00 & 1.6 & 0.41 & 72 \\
Singapore & 0.008 & 0.0021 & -- & 132 \\
Thailand & 9.52 & 3.4 & 1.6 & \\
Vietnam & 7.03 & 6.3 & 0.41 & \\
\hline
\end{tabular}

${ }^{1}$ Harvested area.

We also assess the impact of $\mathrm{N}$-fertilizer on methane emissions. Because added $\mathrm{N}$-fertilizer increases $\mathrm{CH}_{4}$ fluxes in continuously flooded fields and decreases $\mathrm{CH}_{4}$ fluxes in intermittently flooded paddies, globally, we find that $\mathrm{N}$-fertilization has little impact on global emissions, but does affect emissions at the country level. In China, the added impact of $\mathrm{N}$-fertilization decreases emissions by $0.6 \mathrm{Tg} \mathrm{CH}_{4} \mathrm{y}^{-1}$, while in Vietnam it increases emissions by $1 \mathrm{Tg} \mathrm{CH}_{4} \mathrm{y}^{-1}$. The difference is due to the fraction of paddy area under continuous flooding management.

One additional noteworthy result of our methane inventory is the relatively large emissions from Vietnam (Table 1). Emissions are large here because we assigned all of Vietnam's paddy area to continuous flooding management according to Yan et al., (2009). If we set the water management of Vietnam equal to that of China, Vietnam's emissions are halved.

\subsubsection{Nitrous Oxide Maps}

Globally, annual emissions of $\mathrm{N}_{2} \mathrm{O}$ from paddies are about $0.05 \mathrm{Tg} \mathrm{N}_{2} \mathrm{O}$ and the top three emitters are in order China, India, and Bangladesh (Table 1). Interestingly, we find the relation between China and India reversed here, with $\mathrm{N}_{2} \mathrm{O}$ emissions from China being nearly 4 times larger than India's. This finding supports our earlier conclusion, that changing agricultural practices in China are decreasing methane emissions at the expense of nitrous oxide emissions. 
Though the trend towards intermittent flooding depresses $\mathrm{CH}_{4}$ emissions, it elevates $\mathrm{N}_{2} \mathrm{O}$ emissions.

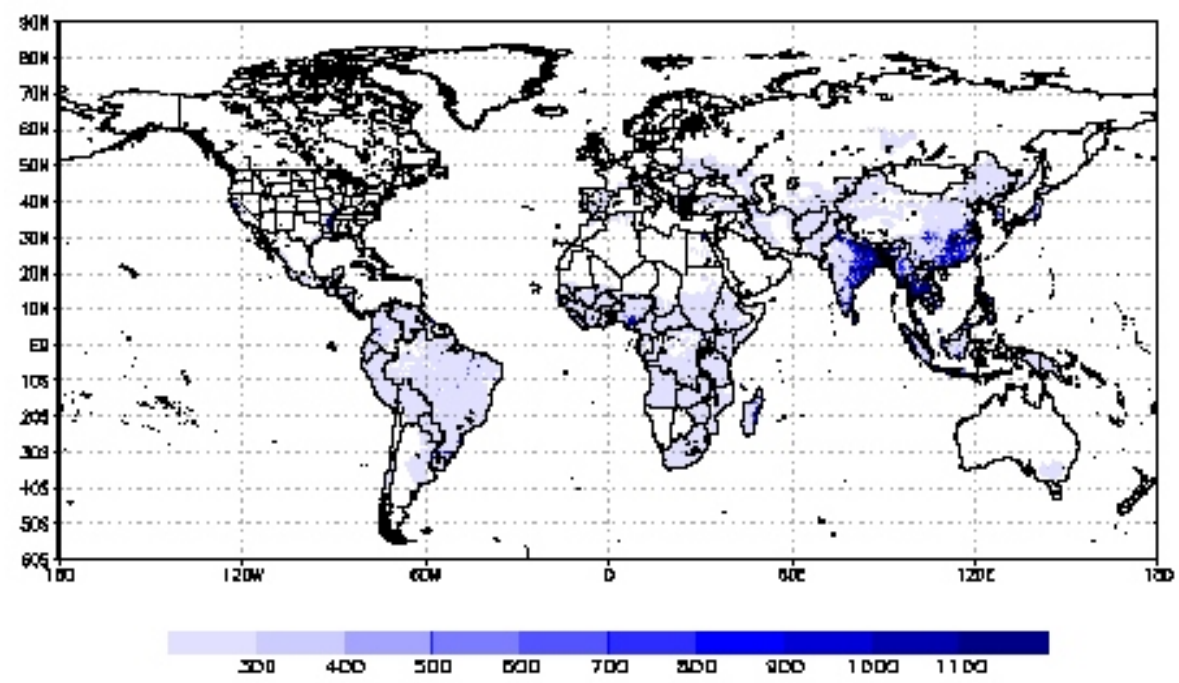

Fig. 8. Methane emissions from rice fields. Units are tonnes $\mathrm{CH}_{4} \mathrm{y}^{-1}$ per grid cell. The size of the grid cells is $5 \mathrm{~min} \times 5 \mathrm{~min}(\sim 10 \mathrm{~km} \times 10 \mathrm{~km}$ at the equator $)$.

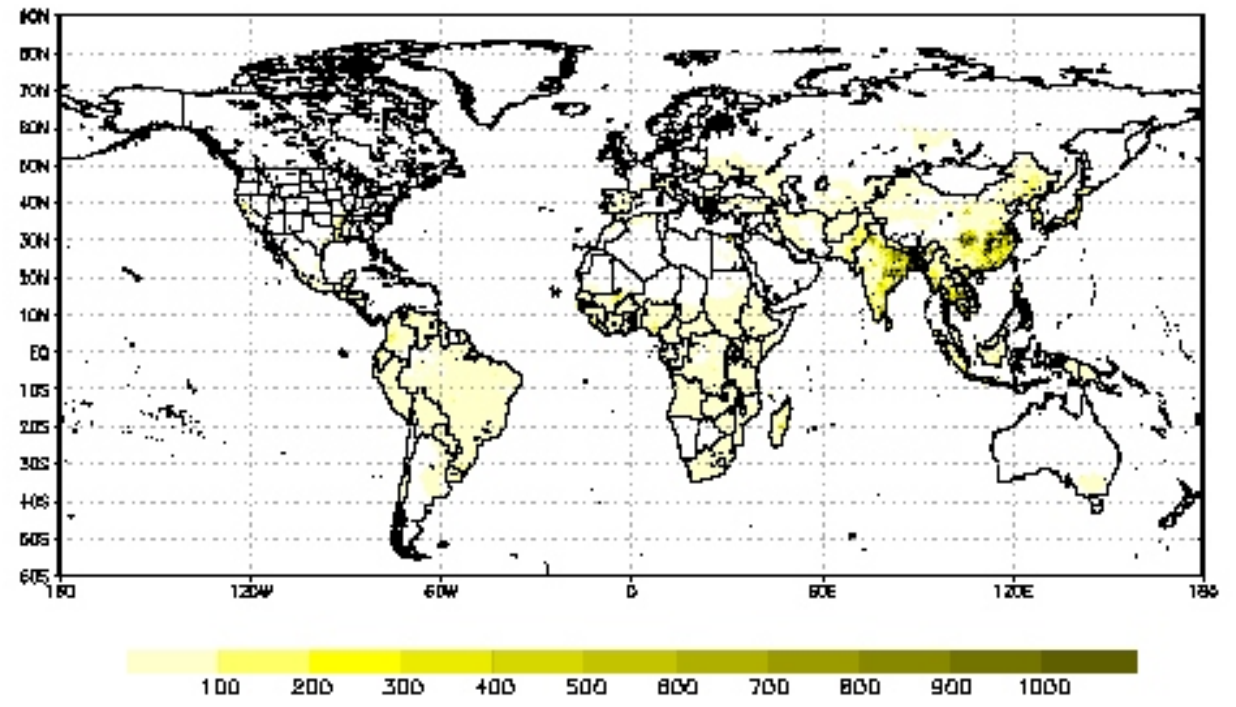

Fig. 9. Nitrous oxide emissions from rice fields. Units are $\mathrm{kg} \mathrm{N}_{2} \mathrm{O} \mathrm{y}^{-1}$ per grid cell. The size of the grid cells is $5 \mathrm{~min} \times 5 \min (\sim 10 \mathrm{~km} \times 10 \mathrm{~km}$ at the equator $)$. 


\subsubsection{Carbon Equivalent Emissions}

We assess the relative importance of paddy emissions to global warming by computing carbon equivalent emissions based on each gas's global warming potential $\left(\mathrm{GWP}_{\mathrm{CH} 4} \sim 20, \mathrm{GWP}_{\mathrm{N} 2 \mathrm{O}} \sim 300\right.$ for a time horizon of 100 years). The carbon equivalency map is shown in Fig. 10 and summarized by country in Table 1 . Worldwide, we estimate that rice paddies emit the equivalent of $950 \mathrm{Tg}$ of carbon dioxide or about $1 \mathrm{Pg}$. This is about $3.5 \%$ of the $28 \mathrm{Pg}$ of $\mathrm{CO}_{2}$ emitted from fossil fuels and cement production. With rice production expected to increase to meet growing populations, the contribution of rice paddies to global warming will continue to rise.

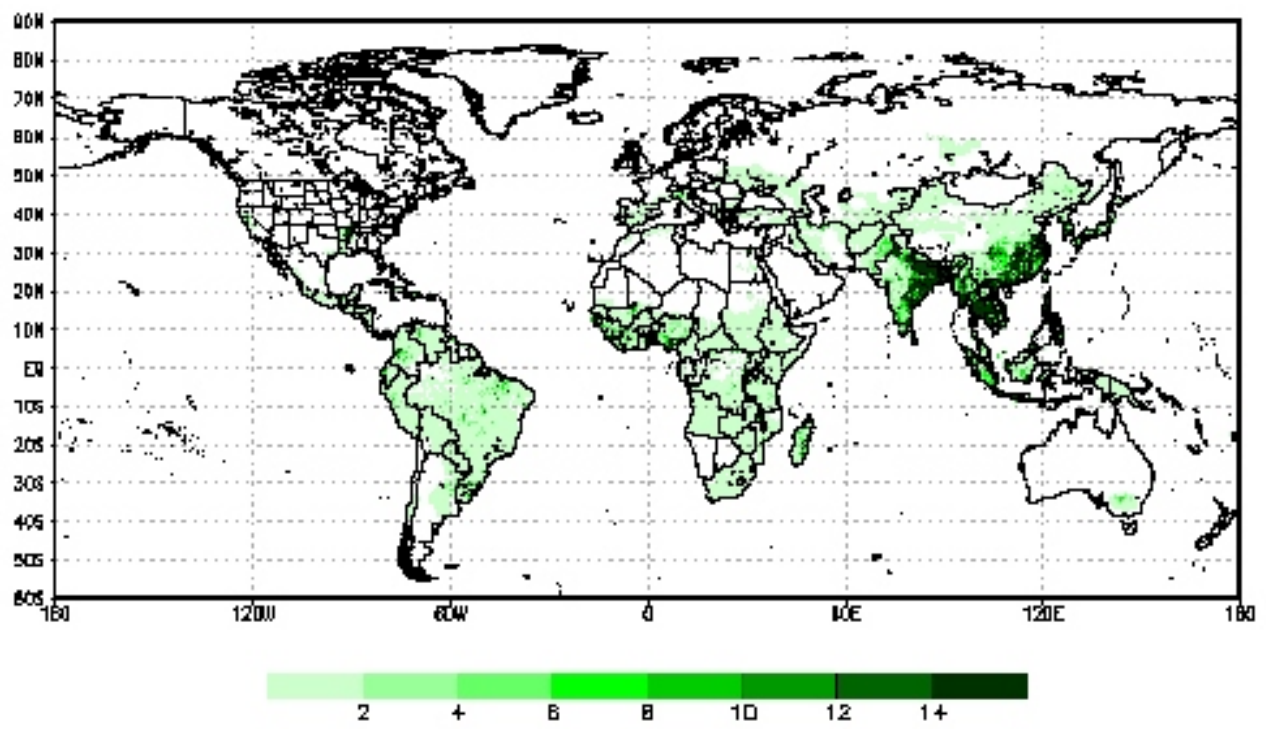

Fig. 10. Equivalent $\mathrm{CO}_{2}$ emissions from rice fields. The emissions are calculated by scaling $\mathrm{CH}_{4}$ and $\mathrm{N}_{2} \mathrm{O}$ emissions by their global warming potentials and summing. Units are $\mathrm{Gg} \mathrm{CO} \mathrm{CO}_{2} \mathrm{y}^{-1}$ per grid cell. The size of the grid cells is $5 \min \times 5 \min (\sim 10 \mathrm{~km} \times 10 \mathrm{~km}$ at the equator)

\subsection{Decreasing Trends From China}

As our experiments have shown, methane emissions from rice fields are controlled by several key factors the most important or which are the application of organic fertilizers and whether the fields are flooded intermittently or continuously. The total annual emissions from any country or the world are thus the product of the area of rice harvested (hectares) and a composite emission factor ( $\mathrm{Tg} /$ hectare/year) that takes into account how the various agricultural practices are distributed in terms of fertilizer use and water management. Over decades the area of rice harvested changes but so does the composite emission factor. The product therefore, may change substantially over decadal time scales. For China at least, there are downward trends of both area 
and emission factor leading to a substantial three fold reduction of annual emissions over the last two decades from perhaps $30 \mathrm{Tg} / \mathrm{yr}$ to around $7 \mathrm{Tg} / \mathrm{yr}$. The changes that cause these reductions would increase nitrous oxide emissions from rice fields as organic fertilizers are replaced with nitrogen based fertilizers. Similar changes are likely to be occurring world-wide. These trends of emissions are probably represented in the observed slowdown of methane trend in the atmosphere and the continuing steady increase of nitrous oxide. Fig 11 shows our estimates of the change of emissions from rice fields in China. The full explanation of these calculations is in the paper by Khalil and Shearer (2006).

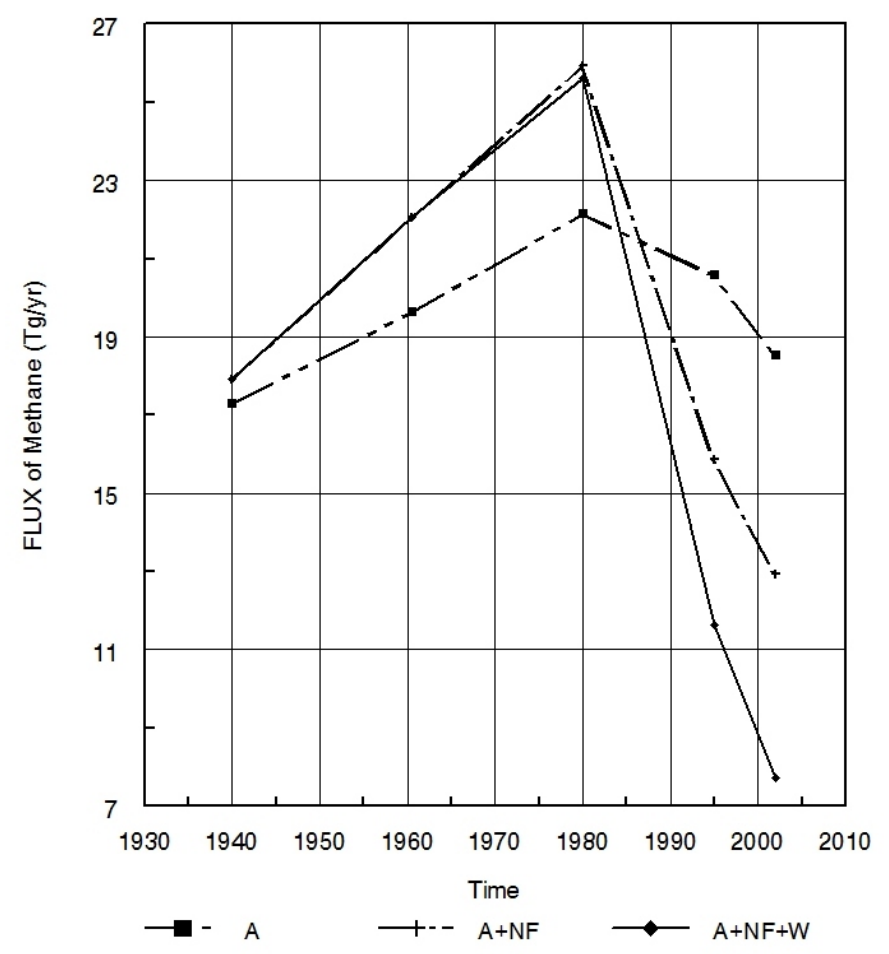

Fig 11. Reducing of methane emissions from rice fields in China over the recent decades. Factors such as those shown in Fig 7 suggest that methane emissions from rice agriculture have declined during the recent decades. Here we estimate the effect from China where nitrogen fertilizers have been replacing the organic manure and other organic amendments, as well as more prevalent practice of intermittent flooding. These trends are a part of the explanation for the stable concentrations of methane that have been observed in recent years, which require the total worldwide emissions to be approximately constant. 


\section{Conclusions}

This was one of the first systematic studies to investigate the major factors that control methane emissions from rice fields and to estimate the numerical values of the parameters that connect emissions to fertilizer use and water management along with other environmental and agricultural variables. Studies in the field, although desirable for many reasons, fail to isolate the effects of individual variables. With controlled studies in a greenhouse significant new information has been obtained as described in this report and will be published in the scientific literature. These data are being used to construct a consistent model of methane emissions from rice fields and by extension, from wetlands, which together constitute some $40 \%$ of the annual emissions of methane from all sources. We have used these results to generate a high spatial resolution grid of methane emissions from rice agriculture and a first attempt has been made at the same assessment for nitrous oxide.

\section{References}

Denman, K.L., G. Brasseur, A. Chidthaisong, P. Ciais, P.M. Cox, R.E. Dickinson, D. Hauglustaine, C. Heinze, E. Holland, D. Jacob, U. Lohmann, S Ramachandran, P.L. da Silva Dias, S.C. Wofsy and X. Zhang, 2007: Couplings Between Changes in the Climate System and Biogeochemistry. In: Climate Change 2007: The Physical Science Basis. Contribution of Working Group I to the Fourth Assessment Report of the Intergovernmental Panel on Climate Change [Solomon, S., D. Qin, M. Manning, Z. Chen, M. Marquis, K.B. Averyt, M.Tignor and H.L. Miller (eds.)]. Cambridge University Press, Cambridge, United Kingdom and New York, NY, USA.

Huang, Y., W. Zhang, X. Zheng, S. Han, and Y. Yu, 2006. Estimates of methane emissions from Chinese rice paddies by linking a model to GIS database, Acta Ecologica Sinica, 26, 980-988.

Khalil, M.A.K. and M.J. Shearer, 2006. Decreasing emissions of methane from rice agriculture. In: Greenhouse Gases and Animal Agriculture: An Update (C.R. Soliva, J. Takahashi, M. Kreuzer, eds.) International Congress Series 1293, Elsevier, The Netherlands, p. 33-41.

Li, C., J. Qiu, S. Frolking, X. Xiao, W. Salas, B.Moore III, S. Boles, Y. Huang, and R. Sass, 2002. Reduced methane emissions from large scale changes in water management of China's rice paddies during 1980-2000, Geophys. Res. Lett., 29(20), 1972, doi:10.1029/2002GL015370.

Matthews, E., I. Fung, and J. Lerner, 1991. Methane emissions from rice cultivation: Geographic and seasonal distribution of cultivated areas and emissions, Global Biogeochem. Cycles, 5, 3-24.

Monfreda C., N. Ramankutty, and J. A. Foley, 2008. Farming the planet: 2. Geographic distribution of crop areas, yields, physiological types, and net primary production in the year 2000, Global Biogeochem. Cycles, 22, GB1022, doi:10.1029/2007GB002947.

Ramankutty, N., A. Evan, C. Monfreda, and J. A. Foley, 2008. Farming the planet: 1. 
Geographic distribution of global agricultural lands in the year 2000", Global Biogeochemical Cycles, 22, GB1003, doi:10.1029/2007GB002952.

Snedecor, G.W., and W.G. Cochran, 1989. Statistical Methods, Eighth Edition. Iowa State University Press, Ames, Iowa.

Yan, X., H. Akiyama, K. Yagi, and H. Akimoto, 2009. Global estimations of the inventory and mitigation potential of methane emissions from rice cultivation conducted using the 2006 Intergovernmental Panel on Climate Change Guidelines, Global Biogeochem. Cycles, 23, GB2002, doi:10.1029/2008GB003299.

Zumft, W.G., and P.M.H. Kroneck, 1990. Metabolism of nitrous oxide. In: Denitrification in Soil and Sediment (N.P. Revsbech and J. Sørensen, eds.) FEMS Symposium No. 56, Plenum Press, N.Y., USA.

\section{Personnel - Education and Research Support}

Brief role and functions of the team members

M.A.K. Khalil, Professor - PI/PD. Theory, experimental design, data analysis, data interpretation, mathematical modeling, global methane and nitrous oxide budgets and project management.

M.J. Shearer, Research Assistant Professor - Laboratory measurements, crop planting and management in the greenhouse, statistical analysis.

Z.Q. Xiong; Research Assistant Professor - Soil scientist, greenhouse experiments at PSU and manager of field experiments in Nanjing, China in collaboration with the Institute of Soil Science, Chinese Academy of Sciences, Nanjing.

C.L. Butenhoff, Research Assistant - Mathematical modeling, computer programing, global extrapolations - upscaling, satellite data applications, spatial and temporal gridded inventories.

R.A. Rasmussen, Professor - Consultant on equipment, instrumentation and laboratory measurements.

Students (Graduate):

Aida Biberic - M.S. (Completed) - Global methane budget - constraint modeling.

Chris Butenhoff - Ph.D (Candidate) - Global Change Science, global upscaling and gridded inventories. 


\section{Publications Resulting From the Project}

"Isotopic signatures and concentration profiles of nitrous oxide in a rice-based ecosystem during the drained crop-growing season.” Z.Q. Xiong, M.A.K. Khalil, G. Xing, M.J. Shearer, C.

Butenhoff. Journal of Geophysical Research, 114, G02012, doi:10.1029/2008/JG000827, 2009.

"Production, oxidation, and emissions of methane from rice fields in China." M.A.K. Khalil, M.J. Shearer, R.A. Rasmussen, C-L. Duan, L-X. Ren., Journal of Geophysical Research, 113, G00A04, doi:10.1029/2007/JG000461, 2008.

"Methane and nitrous oxide emissions from sub-tropical rice agriculture in China." " M.A.K. Khalil, M.J. Shearer, R.A. Rasmussen, L. Xu, J-L. Liu. Journal of Geophysical Research, 113, G00A05, doi:10.1029/2007/JG000462, 2008.

"Spatial Variability of Methane Emissions From Rice Fields and Implications For Experimental Design” M.A.K. Khalil and C.L. Butenhoff, Journal of Geophysical Research, 113, G00A09, doi:10.1029/2007/JG000517, 2008.

"Atmospheric Methane: Concentrations, Trends, and Modeling."Aida Berberic. Thesis: Master of Science in Physics, Portland State University, Portland, Oregon, 2008.

"The atmospheric methane sink.” D.E. Shallcross, M.A.K. Khalil, and C.L. Butenhoff. In: Greenhouse Gas Sinks (D. Reay, C.N. Hewitt, K. Smith and J. Grace, eds.), CABI, Cambridge, MA, p. 171-183, 2007.

"Stratospheric sinks of $\mathrm{N}_{2}$ O." C.L. Butenhoff and M.A.K. Khalil. In: Greenhouse Gas Sinks (D. Reay, C.N. Hewitt, K. Smith and J. Grace, eds.), CABI, Cambridge, MA, p. 207-226, 2007.

"Atmospheric methane: Trends and cycles of sources and sinks." M.A.K. Khalil, C.L. Butenhoff, and R.A. Rasmussen. Environmental Science \& Technology 41, 2131-2137, 2007.

"Global methane emissions from terrestrial plants." C.L. Butenhoff and M.A.K. Khalil. Environmental Science \& Technology, 41, 4032-4037, 2007.

"Nitrous oxide and methane emissions as affected by water, soil and nitrogen." Z.Q. Xiong, G.X. Xing, and Z.L. Zhu. Pedosphere 17(2), 146-155, 2007.

"Decreasing emissions of methane from rice agriculture." M.A.K. Khalil and M.J. Shearer. In: Greenhouse Gases and Animal Agriculture: An Update (C.R. Soliva, J. Takahashi, M. Kreuzer, eds.) International Congress Series 1293, Elsevier, The Netherlands, p. 33-41, 2006. 